\title{
Microvesicles containing miR-34a induce apoptosis of proximal tubular epithelial cells and participate in renal interstitial fibrosis
}

\author{
HONGYAN LI, YUEXIA XU, QIN ZHANG, HONGFANG XU, YAN XU and KAI LING \\ Department of Nephrology, The First People's Hospital of Wujiang, Wujiang Hospital \\ Affiliated to Nantong University, Suzhou, Jiangsu 215200, P.R. China
}

Received May 30, 2018; Accepted January 15, 2019

DOI: $10.3892 /$ etm.2019.7197

\begin{abstract}
Function and potential mechanism of microvesicles (MVs) containing microRNA34a in renal interstitial fibrosis were investigated. A rat model of renal interstitial fibrosis was established by unilateral ureteral ligation (UUO).Rat proximal tubular epithelial cell line (NRK-52E) was used to explore the effect of MVs containing microRNA-34a on tubular epithelial cells during fibrosis, which were secreted by tubulointerstitial fibroblasts. Regardless of the UUO renal interstitial fibrosis model, or the TGF- $\beta 1$-treated renal tubular epithelial cells, microRNA-34a was increased in the MVs secreted by tubulointerstitial fibroblasts. miR-34a could be transmitted through the damaged tubule basement membrane to proximal tubular epithelial cells, where it induced apoptosis of renal tubular epithelial cells by inhibiting the expression of $\mathrm{Bcl}-2$, further aggravating renal interstitial fibrosis. MicroRNA-34a secreted by damaged renal interstitial fibroblasts can promote renal tubular epithelial cell apoptosis and participate in renal interstitial fibrosis by inhibiting Bcl-2.
\end{abstract}

\section{Introduction}

The final common pathological result of chronic kidney disease (CKD) is renal interstitial fibrosis $(1,2)$, which is characterized by tubular atrophy and accumulation of extracellular matrix (3). Apoptosis of tubular epithelial cells is one of the causes of tubular atrophy and interstitial fibrosis (4-7). Hypoxia, oxidative stress, and TGF- $\beta 1$ treatment are all leading causes of apoptosis in the model of unilateral ureteral obstruction (UUO)-induced renal interstitial fibrosis $(8,9)$, which can promote inflammatory reactions

Correspondence to: Dr Kai Ling, Department of Nephrology, The First People's Hospital of Wujiang, Wujiang Hospital Affiliated to Nantong University, 169 Park Road, Songling, Wujiang, Suzhou, Jiangsu 215200, P.R. China

E-mail: pjfuj813@163.com

Key words: miR-34a, Bcl-2, apoptosis, fibrosis and increase synthesis of extracellular matrix, eventually leading to renal interstitial fibrosis. Factors that can reduce apoptosis such as hepatocyte growth factor (HGF) and bone morphogenetic protein-7 (BMP-7) can delay renal interstitial fibrosis $(6,10,11)$. However, the molecular mechanism underlying apoptosis of renal tubular epithelial cells remains unknown.

MicroRNAs are endogenous non-coding small RNAs that are widely present in eukaryotic organisms and play an important role in renal development and renal homeostasis (12-14). Recent studies have shown positive feedback regulation between miRNA-34 family (miR-34s) and tumor suppressor protein $\mathrm{p} 53$, suggesting that miRNA-34 may be involved in the regulation of tumor cell apoptosis $(15,16)$. Mature miR-34s in mammals are divided into three types, miR-34a, miR-34b, and miR-34c. miR-34a is the most widely distributed and has the highest expression. miR-34a can promote cell apoptosis by inhibiting Bcl-2 in hepatoma and colorectal cancer cells $(17,18)$. However, the role of miR-34a in kidney diseases has not been widely studied, so we hypothesized that miR-34a may regulate renal tubular epithelial cells apoptosis during renal interstitial fibrosis.

miRNAs not only regulate the expression of target genes directly, but also regulate the expression of target genes in other cells through the delivery by microvesicles (MVs). In recent years, MVs have attracted wide attention as the most important link between cells (19). miRNAs found in serum derived from tumor cell MVs have been shown to be associated with tumor metastasis and apoptosis (20-23).

In this study, UUO was used as a renal interstitial fibrosis model and TGF- $\beta 1$-treatment was used as an attempt to investigate the role of MVs containing miR-34a in regulating renal tubular epithelial cell apoptosis. We found that miR-34a was mainly distributed in renal tubular interstitial cells and that its expression was significantly increased in obstructed renal tissues after obstruction. TGF- $\beta 1$ treatment upregulated miR-34a expression in mesenchymal fibroblasts.miR-34a derived from mesenchymal fibroblast MVs can be transmitted to proximal tubular epithelial cells through the damaged tubular basement membrane and induced apoptosis through inhibition of Bcl-2 expression. This study provides a new molecular mechanism for microRNA-mediated apoptosis of renal tubular epithelial cells and a new theoretical basis for the pathogenesis of renal interstitial fibrosis. 


\section{Materials and methods}

Mice. Male CD-1 mice weighing 18-20 g were purchased from the Nanjing University Laboratory, and were raised according to the experimental animal feeding standard. The mice were randomly divided into 4 groups, which were sham-operated group, UUO groups for 1,3 , and 7 days ( $n=6$ each group). Mice were sacrificed on 1, 3 and 7 days after operation, respectively and the kidney tissues were obtained. This study was approved by The Animal Care and Use Review Committee of Wujiang Hospital Affiliated to Nantong University (Suzhou, China).

Cell culture and treatment. The rat proximal tubularepithelial cells (NRK-52E) and the renal interstitial fibroblast cells (NRK-49F) were planted on a petri dish and cultured at $37^{\circ} \mathrm{C}, 5 \% \mathrm{CO}_{2}$ environment. The culture medium was DMEM/F12 (12400-024), containing $10 \%$ fetal bovine serum (FBS; 16000-044) and 1\% penicillin-streptomycin (15140-122) (all from Life Technologies; Thermo Fisher Scientific, Inc., Waltham, MA, USA). When cells grew to $80 \%$ confluency, the culture medium was replaced with serum-free medium for $16 \mathrm{~h}$. After $16 \mathrm{~h}$, the serum-free medium was replaced again, and TGF $\beta 1$ (240B; R\&D Systems, Inc., Minneapolis, MN, USA) was added to stimulate the cells. Cells and supernatants were collected at different times. The control group was collected in the same way.

Microvesicle extraction. We used ultracentrifugation to extract the MVs in the cell supernatant. Cell supernatants were centrifuged at $300 \mathrm{xg}$ for $10 \mathrm{~min}$ at $4^{\circ} \mathrm{C}$, then $1,200 \mathrm{x}$ for $20 \mathrm{~min}$ and $10,000 \mathrm{x} g$ for $30 \mathrm{~min}$. The supernatant was collected, and then centrifuged at $4^{\circ} \mathrm{C}$ for $110,000 \times \mathrm{g}$ for $60 \mathrm{~min}$. Finally, the precipitate was the MVs. The MVs were resuspended with appropriate phosphate-buffered saline (PBS). TRIzol reagent (10296-028; Life Technologies; Thermo Fisher Scientific, Inc.) was used to extract mRNA of MVs.

miRNA detection by reverse transcriptase-quantitative polymerase chain reaction $(R T-q P C R)$. mRNA was extracted from tissues or cells using TRIzol, and the cDNA was synthesized using miScript RT II kit (15596-026; Life Technologies; Thermo Fisher Scientific, Inc.), and was stored at $-20^{\circ} \mathrm{C}$. RT-qPCR was performed using the miScript SYBR-Green PCR kit (28073; Qiagen, Duesseldorf, Germany) to investigate the relative gene expressions.

Plasmid transfection. The cells were planted in 6-well plate, and cultured in DMEM/F12 with $10 \%$ FBS. When $90-95 \%$ confluency was reached, $1.5 \mathrm{ml}$ of serum-free and antibiotic-free culture medium was replaced per well. A total of $2.5 \mu \mathrm{g}$ plasmid (pGPH1/GFP/NEO-BCL-2 shRNA; Shanghai Yingjun Biotech Company, Shanghai, China) and $5 \mu$ l Liposome 2000 were diluted with $250 \mu$ l Opti-MEM (serum reduced medium) and incubated for $5 \mathrm{~min}$ at room temperature, respectively. The two transfection mixtures were mixed and incubated at room temperature for $20 \mathrm{~min}$. A total of $500 \mu \mathrm{l}$ of transfection mixture was added into each well, and gently mixed with the cell culture medium. Then the cells were incubated in $\mathrm{CO}_{2}$ incubator. The medium was changed $6 \mathrm{~h}$ later, then the cells were stimulated with or without TGF- $\beta 1$. After 48 h, cells were collected.
TUNEL staining. Apoptosis of tissues and cells was detected using the TACS2 TdT-DAB/Fluor in situ apoptosis detection kit (no. 4812-30-K; Trevigen, Gaithersburg, MD, USA). Briefly, a coverslip was pre-placed in a 24 -well plate, then cells were plated on the coverslips. The cells were incubated with $50 \mu \mathrm{l}$ proteinase $\mathrm{K}$ for $30 \mathrm{~min}$ at room temperature. After being washed in deionized water, the cells were immersed in $1 \mathrm{X}$ TdT labeling buffer for another $5 \mathrm{~min}$. Then, the cells were incubated with $50 \mu$ l labeled reaction solution in a wet box at $37^{\circ} \mathrm{C}$ for $1 \mathrm{~h}$. The stop solution $1 \mathrm{X}$ TdT was dipped in medium at room temperature, for $5 \mathrm{~min}$. After washing twice with deionized water, the cells were incubated with $50 \mu \mathrm{l}$ Strep-DAB/Fluor solution for $20 \mathrm{~min}$ in the dark. Finally, the cells were washed with 1X PBS twice. A Nikon Eclipse 80i (fluorescence) microscope equipped with a DS-Ril (Nikon Corporation, Tokyo, Japan) digital camera was used to observe and photograph the cells. A total of 20 random fields of each sample were selected for capturing images under the microscope at a magnification of $\mathrm{x} 200$. The number of positive cells was counted and the average value was calculated to make a histogram of the number of TUNEL-positive cells.

Immunoblot analysis. Cells were ground or collected with cell scraper to obtain the total protein of cells by lysate on ice, then centrifuged at $16,000 \mathrm{xg}$ at $4^{\circ} \mathrm{C}$ for $30 \mathrm{~min}$. Bicinchoninic acid (BCA) Protein Assay kit (Beyotime, Shanghai, China) was used to measure protein concentration. Followed by sodium dodecyl sulphate-polyacrylamide gel electrophoresis (SDS-PAGE), the immunoblots were incubated with the antibodies of fibronectin (FN; cat. no. 3648; Sigma-Aldrich; Merck KGaA, Darmstadt, Germany), CD34 (cat. no. sc-15363; Santa Cruz Biotechology, Inc., Santa Cruz, CA, USA), p-caspase-3 (cat. no. ab59425), caspase-3 (cat. no. ab13847; both from Abcam, Cambridge, MA, USA), Bcl-2 (cat. no. 2870; Cell Signaling Technology, Inc., Danvers, MA, USA) and tubulin (cat. no. ab7291; Abcam).

Statistical analysis. Statistical analysis was performed using Statistical Product and Service Solutions (SPSS) 16.1 statistical software (SPSS, Inc., Chicago, IL, USA). Measurement data were expressed as mean \pm standard error. One-way ANOVA (post-hoc LSD or SNK) was used for comparison between multiple experimental groups. The experimental data were compared between the two groups using Student's t-test. $\mathrm{P}<0.05$ was considered to indicate a statistically significant difference.

\section{Results}

Increased expression of miR-34a in obstructed renal tissue and MVs. A large amount of cell apoptosis occurred in a UUO-induced renal interstitial fibrosis model. We first detected the expression of miR-34a in renal tissue, and found that $\mathrm{miR}-34 \mathrm{a}$ expression began to increase on the first day after surgery, and had a time-dependent elevation (Fig. 1A). At the same time, the mRNA expression of miR-34a in renal tissue was also significantly increased after treatment; it was also time-dependent (Fig. 1B).

To determine whether the increased expression of miR-34a in the obstructed kidney was secreted into MVs, we extracted MVs from the kidney. As shown in Fig. 1C, the expression 

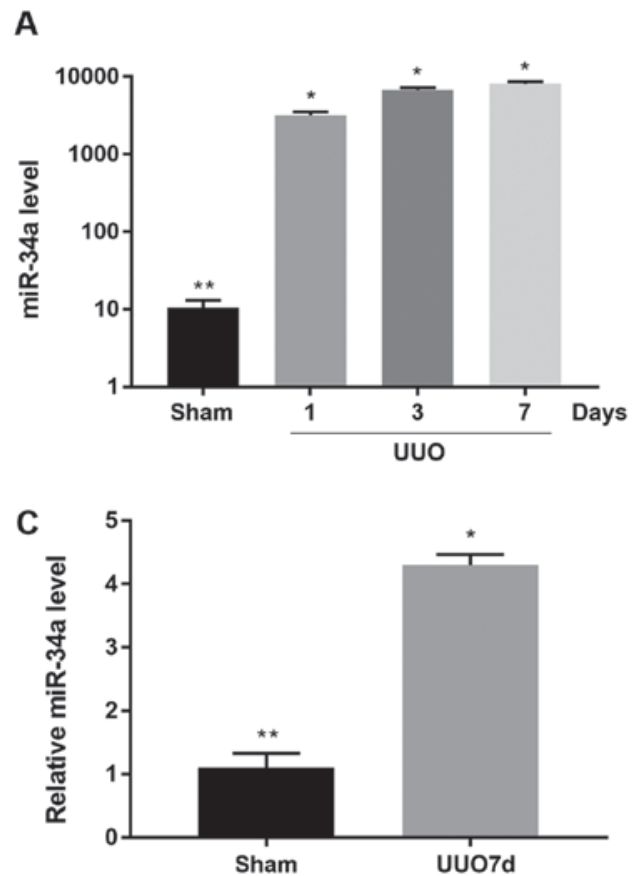

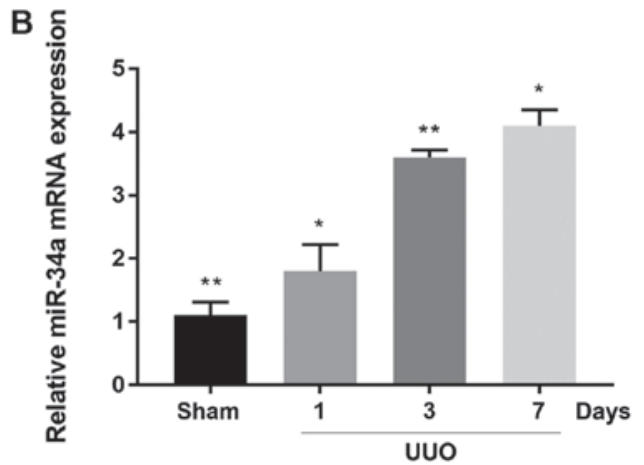

D

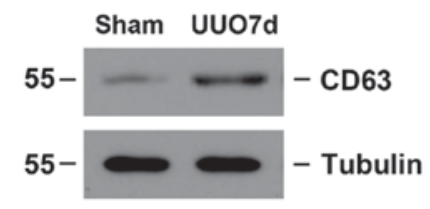

Figure 1. Increased expression of miR-34a in obstructed renal tissue and microvesicles. (A) The miR-34a level of kidneys in each group ("P<0.05, $\left.{ }^{* *} \mathrm{P}<0.01\right)$. (B) The relative miR-34a mRNA in each group ("P<0.05, $\left.{ }^{* *} \mathrm{P}<0.01\right)$. (C) The miR-34a level of MVs in each group $\left({ }^{*} \mathrm{P}<0.05,{ }^{* *} \mathrm{P}<0.01\right)$. (D) The protein expressions of CD63 in kidneys of each group. MVs, microvesicles.

of miR-34a in the MVs of the obstructed kidney was significantly increased (Fig. 1C). CD63 is a marker protein of MVs. CD63 protein expression represents the content of MVs. The results showed that compared with the sham-operated renal tissue, the expression of CD63 was increased in obstructed kidney tissue (Fig. 1D), suggesting that in the UUO renal interstitial fibrosis model, the secretion of MVs in the kidney was increased. Thus, these data demonstrated that in the UUO-induced renal interstitial fibrosis model, MVs containing microRNA-34a were increased.

miR-34a is increased in TGF- $\beta 1$-treated fibroblasts and aggravated renal interstitial fibrosis. To clarify the expression of miR-34a in the renal tissue after obstruction, we treated NRK-52E and NRK-49F cells with TGF- $\beta 1$ to observe the expression of miR-34a. Firstly, we stimulated cells with different concentrations of TGF- $\beta 1$ for $24 \mathrm{~h}$ and extracted MVs from cell culture fluid, then we found that miR-34a expression was significantly increased in fibroblasts compared to the control group. The cells treated with TGF- $\beta 1$ at a concentration of $5 \mathrm{ng} / \mathrm{ml}$ had the highest miR-34a expression. However, miR-34a expression in tubule epithelial cells did not change significantly (Fig. 2A). We then treated both cell lines with $5 \mathrm{ng} / \mathrm{ml}$ TGF- $\beta 1$ for different time-points to detect the expression of miR-34a in MVs from cell culture fluid. A similar result was found that the expression of miR-34a was significantly increased in fibroblasts and was time-dependent, whereas the expression of miR-34a was slightly increased in tubule epithelial cells (Fig. 2B). The MVs collected from the culture fluid of NRK-49F cells were treated with TGF- $\beta 1$ at a concentration of $5 \mathrm{ng} / \mathrm{ml}$, then stimulated NRK-52E cells with MVs at a concentration of $200 \mathrm{nmol} / 1$ for different times, then we found the expression of $\alpha$-SMA and FN were increased and were time-dependent (Fig. 2C). Similar results were found in the mRNA expression of $\alpha$-SMA and FN which were increased in experimental groups (Fig. 2D and E).

miR-34a induces apoptosis of proximal tubular epithelial cells. To directly verify whether miR-34a promotes apoptosis of proximal tubular epithelial cells, we transfected miR-34a mimic and inhibitor to observe apoptosis to achieve miR-34a overexpression and knockdown. First, we tested the transfection efficiency. The results showed that transfection of miR-34a inhibitor significantly downregulated the expression of miR-34a in NRK-52E cells (Fig. 3A), while miR-34a mimic transfection significantly increased the expression of miR-34a (Fig. 3B). We used TUNEL staining to compare the apoptosis of proximal tubular epithelial cells after transfection with $80 \mathrm{nmol} / \mathrm{l}$ negative control, miR-34a mimic and miR-34a inhibitor. The results showed that the number of apoptotic cells in the mimic group was significantly increased (Fig. 3C), while the number of apoptosis in the inhibitor transfected group was decreased. The same result was obtained by counting the number of cells (Fig. 3D).

Caspase- 3 is a marker of apoptosis. Therefore, we observed the effect of miR-34a on apoptosis of renal tubular epithelial cells by observing the expression of caspase-3. The results showed that when miR34a was upregulated in NRK-52E cells, the expression of caspase-3 protein was significantly increased as well, whereas after downregulating miR-34a, the expression of caspase-3 protein was decreased (Fig. 3E). The mRNA levels of caspase-3 in each group were found to be consistent with the protein results. These results suggested that miR-34a can promote renal tubular epithelial cell apoptosis.

miR-34a participates in renal interstitial fibrosis by inhibiting apoptosis of target gene Bcl-2. Bioinformatics studies have 

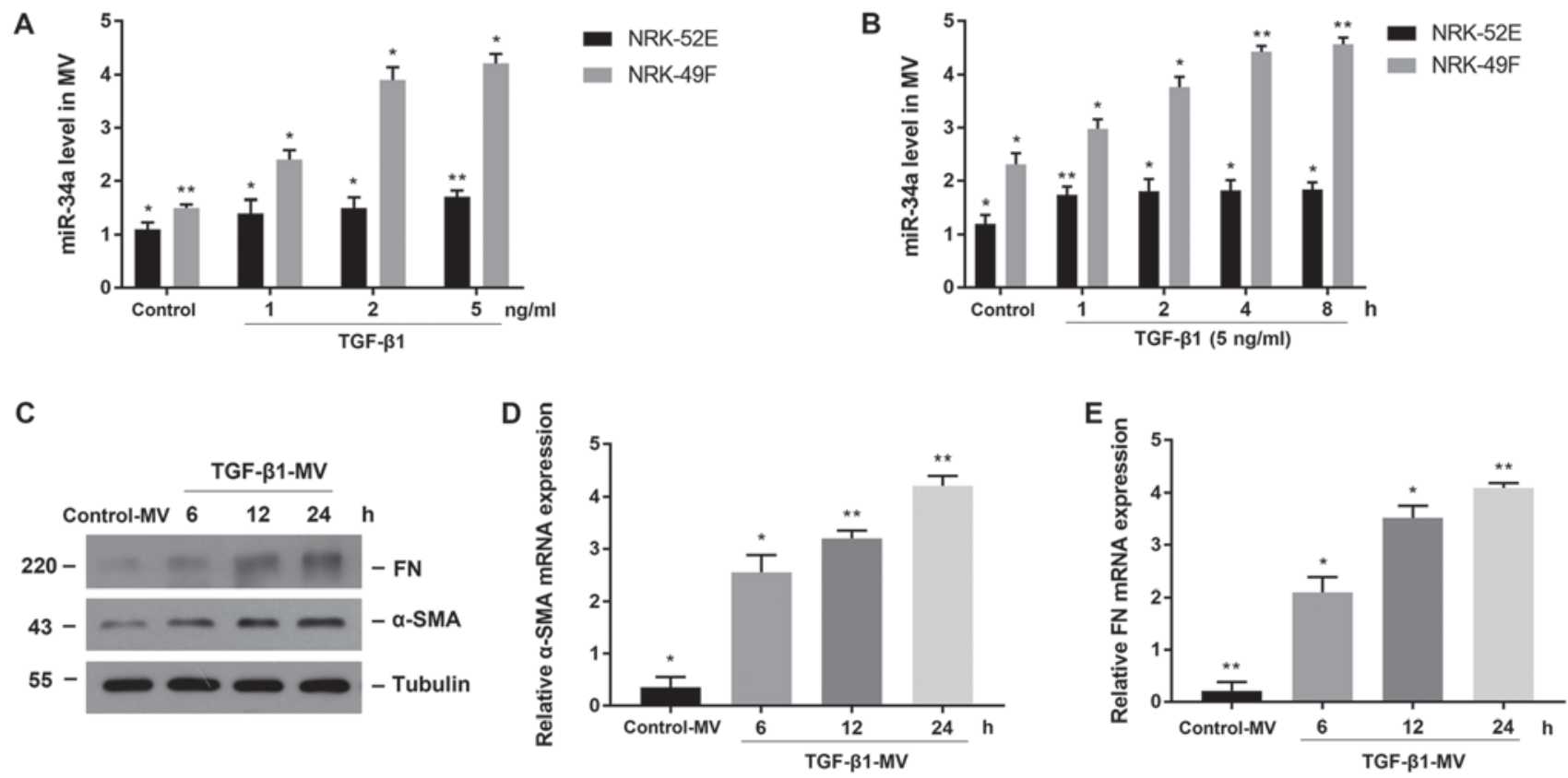

Figure 2. miR-34a was increased in TGF- $\beta 1$-treated fibroblasts and aggravated renal interstitial fibrosis. (A) The miR-34a level in MVs of cell culture fluid in each group $\left({ }^{*} \mathrm{P}<0.05,{ }^{* *} \mathrm{P}<0.01\right)$. (B) The miR-34a level in MVs of cell culture fluid in each group $\left({ }^{*} \mathrm{P}<0.05,{ }^{* *} \mathrm{P}<0.01\right)$. (C) The protein expression of FN, $\alpha$-SMA in NRK-52E cells of each group. (D) The relative $\alpha$-SMA mRNA in each group $\left({ }^{*} \mathrm{P}<0.05,{ }^{* * *} \mathrm{P}<0.01\right)$. (E) The relative FN mRNA in each group $\left({ }^{*} \mathrm{P}<0.05\right.$, $\left.{ }^{* *} \mathrm{P}<0.01\right)$. MVs, microvesicles; FN, fibronectin.

\section{A}

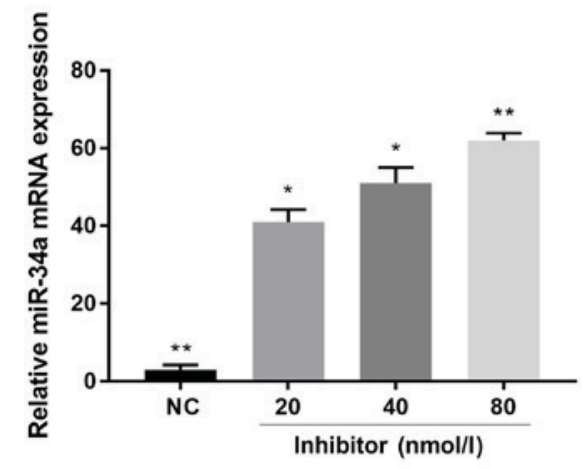

B

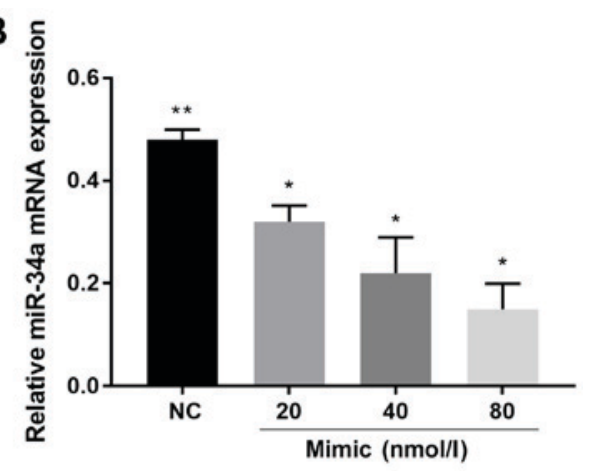

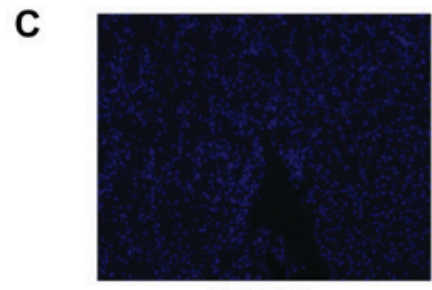

Inhibitor

D

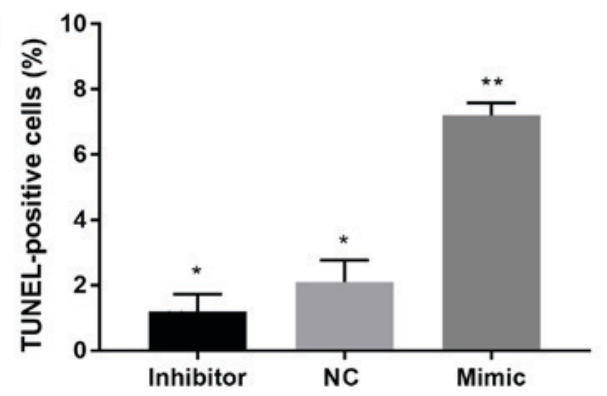

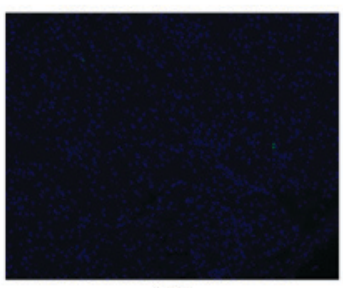

NC

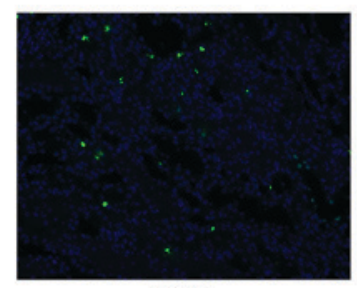

Mimic

E

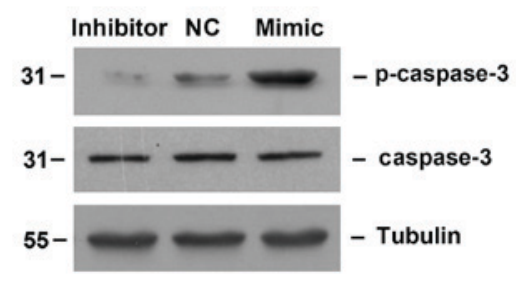

Figure 3. miR-34a induces apoptosis of proximal tubular epithelial cells. (A) The relative miR-34a mRNA in NRK-52E cells treated with miR-34a inhibitors in each group $\left({ }^{*} \mathrm{P}<0.05,{ }^{* *} \mathrm{P}<0.01\right)$. (B) The relative miR-34a mRNA in NRK-52E cells treated with miR-34a mimics in each group $\left({ }^{*} \mathrm{P}<0.05\right.$, $\left.{ }^{* *} \mathrm{P}<0.01\right)$. (C) The result of TUNEL staining in NRK-52E cells. (D) The percentage of NRK-52E cells that were stained positive $\left({ }^{*} \mathrm{P}<0.05,{ }^{* *} \mathrm{P}<0.01\right)$. (E) The protein expression of p-caspase-3, and caspase-3 in NRK-52E cells in each group. 
A

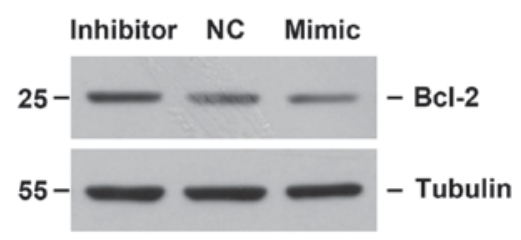

C 으

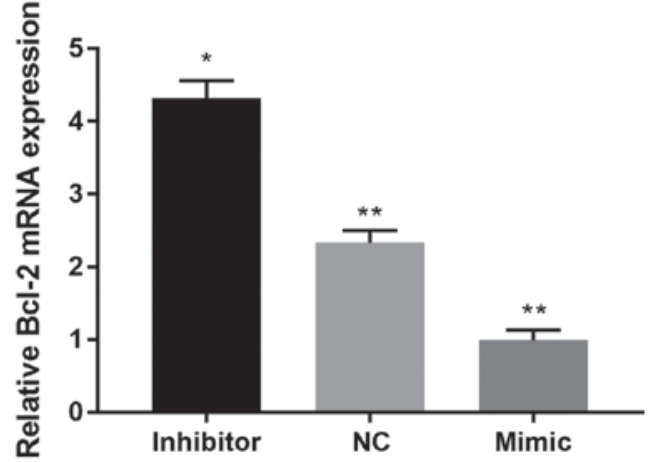

B

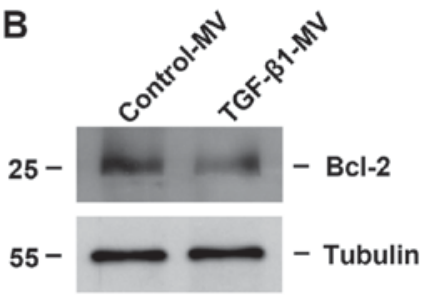

D

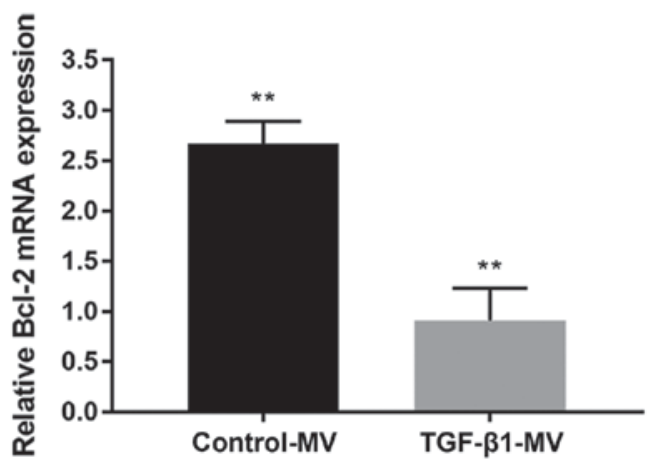

Figure 4. miR-34a participates in renal interstitial fibrosis by inhibiting apoptosis of target gene Bcl-2. (A) The protein expression of Bcl-2 in NRK-52E cells in each group. (B) The protein expression of Bcl-2 in NRK-52E cells treated with MVs in each group. (C) The relative Bcl-2 mRNA in NRK-52E cells in each group $\left({ }^{*} \mathrm{P}<0.05,{ }^{* * *} \mathrm{P}<0.01\right)$. (D) The relative Bcl-2 mRNA in NRK-52E cells treated with MVs in each group ( $\left.\mathrm{P}<0.05,{ }^{* * *} \mathrm{P}<0.01\right)$. MVs, microvesicles.
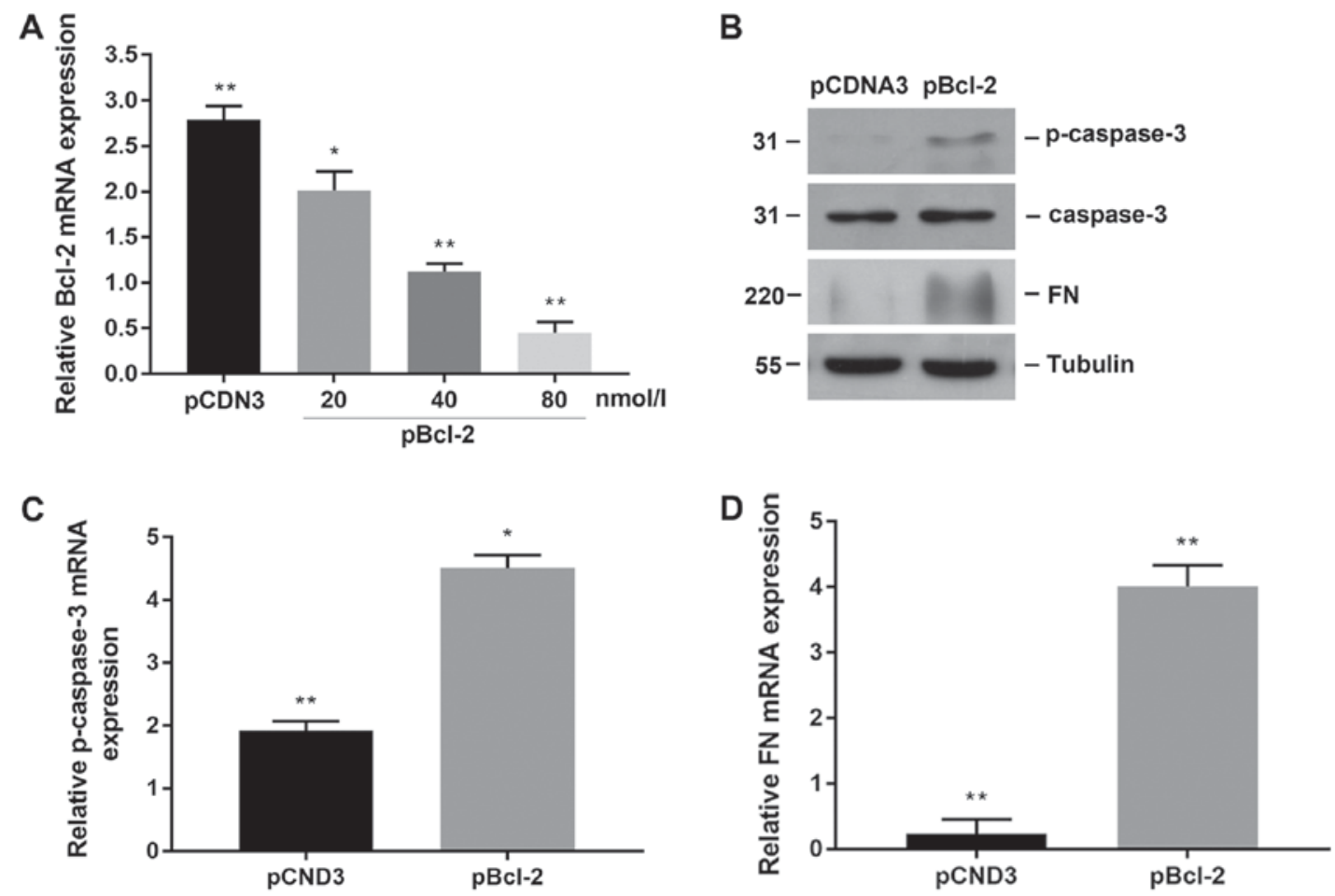

Figure 5. Downregulated Bcl-2 induces apoptosis of proximal tubular epithelial cells. (A) The relative Bcl-2 mRNA in NRK-52E cells in each group ("P $<0.05$, ${ }^{* *} \mathrm{P}<0.01$ ). (B) The protein expression of p-caspase-3, caspase-3, FN in NRK-52E cells in each group. (C) The relative p-caspase-3 mRNA in NRK-52E cells in each group ( $\left.{ }^{*} \mathrm{P}<0.05,{ }^{* *} \mathrm{P}<0.01\right)$. (D) The relative FN mRNA in NRK-52E cells in each group $\left({ }^{*} \mathrm{P}<0.05,{ }^{* *} \mathrm{P}<0.01\right)$. FN, fibronectin.

shown that $\mathrm{Bcl}-2$ is the target protein of miR-34a. Previous studies have confirmed that miR-34a regulates the expression of Bcl-2 in tumor cells $(17,18,24)$. We then hypothesize whether miR-34a regulates apoptosis through $\mathrm{Bcl}-2$. We found that transfection with miR-34a mimic inhibited Bcl-2 protein expression, whereas transfection with miR-34a inhibitor increased Bcl-2 protein expression (Fig. 4A). Similarly, at the gene level, Bcl-2 mRNA levels decreased when miR-34a was upregulated, whereas Bcl-2 mRNA levels increased when miR-34a was downregulated (Fig. 4B). Later, we treated NRK-49F and NRK-52E cells with TGF- $\beta 1$ and found that Bcl-2 protein levels and mRNA levels were all reduced (Fig. 4C and D). 
Downregulated Bcl-2 induces apoptosis of proximal tubular epithelial cells. Previously, we found that upregulation of miR-34a or TGF- $\beta 1$ treatment of NRK-49F micro-vessels can inhibit the expression of $\mathrm{Bcl}-2$ in proximal tubular epithelial cells and induce apoptosis. Then we transfected Bcl-2-specific plasmids to downregulate the expression of Bcl-2 in NRK-52E cells to observe whether apoptosis and fibrosis were further aggravated. We first observed the transfection efficiency of different concentrations of plasmids. We selected a concentration of $80 \mathrm{nmol} / \mathrm{l}$. After treatment of NRK-52E $24 \mathrm{~h}$, we found that downregulation of $\mathrm{Bcl}-2$ increased the expression of p-caspase-3 and promoted interstitial fibrosis (Fig. 5B). Similar results were found in mRNA level analysis (Fig. 5C and D). The data show that the downregulation of $\mathrm{Bcl}-2$ can promote apoptosis of proximal tubular epithelial cells and aggravate renal interstitial fibrosis.

\section{Discussion}

Renal interstitial fibrosis is a common pathological result of CKD, in which apoptosis of renal tubular epithelial cells plays an important role. However, the molecular mechanism is still not clear. Apoptosis, a programmed cell death, is a common form of cell death (25). Many studies have shown that there is abundant apoptosis of cells in various fibrotic organs, suggesting that apoptosis is likely to induce and promote the occurrence and development of organ tissue fibrosis (26). Renal interstitial fibrosis is characterized by tubular atrophy and extracellular accumulation of tubulointerstitial cells (3). Apoptosis of renal tubular epithelial cells is one of the causes of renal tubular atrophy and tubulointerstitial fibrosis (5-7). Previous studies have found evidence of apoptosis in fibrotic kidney tissue by detecting changes in cellular DNA, mitochondria, cell membranes, and cell morphology.

Recent studies have found that miR-34s can regulate tumor cell apoptosis. Among them, the transcriptional expression of miR-34a alone is most widely distributed in various tissues. Bcl-2 is an important anti-apoptosis gene in caspase cell apoptosis pathway. Studies have shown that Bcl-2 expression was inhibited after miR-34s transfection into colon cancer cells. After silencing of miR-34 expression, the expression of Bcl-2 was increased and the anti-apoptotic ability of cells was enhanced (18). Therefore, we hypothesize that miR-34a may also have a role in apoptosis of renal tubular epithelial cells.

To investigate whether miR-34a is involved in the regulation of renal tubular epithelial cell apoptosis, we first examined the expression of miR-34a in the UUO renal interstitial fibrosis model. As a result, we found that the expression of miR-34a as well as the MVs was significantly increased in the renal tissue. Afterwards, we found that MVs containing miR-34a also increased significantly. Subsequently, we used in vitro experiments to detect the distribution of miR-34a. We used TGF- $\beta 1$ to treat NRK-49F and NRK-52E cells to alter their phenotypes, producing extracellular matrix and promoting fibrosis. We found that miR-34a was only significantly increased in interstitial fibroblasts, suggesting that miR-34a is mainly distributed in interstitial fibroblasts but not in tubule epithelial cells. Studies have confirmed that TGF- $\beta 1$ can be transmitted from injured epithelial cells to fibroblasts and induce renal interstitial fibrosis (27). Therefore, we hypothesize that in the obstruction model, the tubule basement membrane was broken and lost its integrity, allowing miR-34a to pass from the mesenchymal fibroblasts to the renal tubular epithelial cells, inducing apoptosis of the renal tubular epithelial cells and promoting renal interstitial fibrosis.

In conclusion, this study shows that in the process of renal interstitial fibrosis, interstitial fibroblasts can secrete miR-34a-containing MVs and transmit signals to renal tubular epithelial cells through the ruptured basement membrane. miR-34a can inhibit the target protein Bcl-2, activate caspase apoptosis pathway, induce apoptosis of renal tubular epithelial cells, and promote renal interstitial fibrosis. MVs containing miRNAs serve as an important molecular platform for mediating cells, helping to further understand the molecular mechanisms of renal tubular epithelial cell apoptosis and tubulointerstitial fibrosis. Our identification of miR-34a in renal interstitial fibrosis suggests miR-34a mimics or inhibitors as potential therapeutics for treating renal interstitial fibrosis.

\section{Acknowledgements}

Not applicable.

\section{Funding}

No funding was received.

\section{Availability of data and materials}

All data generated or analyzed during this study are included in this published article.

\section{Authors' contributions}

HL and KL designed the study and performed the experiments, YuX, QZ and HX established the animal models, HX and YaX collected the data, HL and YuX analyzed the data, HL and KL prepared the manuscript. All authors read and approved the final study.

\section{Ethics approval and consent to participate}

This study was approved by The Animal Care and Use Review Committee of Wujiang Hospital Affiliated to Nantong University (Suzhou, China).

\section{Patient consent for publication}

No patients participated in this study.

\section{Competing interests}

The authors declare that they have no competing interests.

\section{References}

1. Liu Y: New insights into epithelial-mesenchymal transition in kidney fibrosis. J Am Soc Nephrol 21: 212-222, 2010.

2. Zeisberg M and Neilson EG: Mechanisms of tubulointerstitial fibrosis. J Am Soc Nephrol 21: 1819-1834, 2010. 
3. Bohle A, Christ H, Grund KE and Mackensen S: The role of the interstitium of the renal cortex in renal disease. Contrib Nephrol 16: 109-114, 1979.

4. Johnson A and DiPietro LA: Apoptosis and angiogenesis: An evolving mechanism for fibrosis. FASEB J 27: 3893-3901, 2013.

5. Docherty NG, O'Sullivan OE, Healy DA, Fitzpatrick JM and Watson RW: Evidence that inhibition of tubular cell apoptosis protects against renal damage and development of fibrosis following ureteric obstruction. Am J Physiol Renal Physiol 290: F4-F13, 2006.

6. Liu Y: Hepatocyte growth factor in kidney fibrosis: Therapeutic potential and mechanisms of action. Am J Physiol Renal Physiol 287: F7-F16, 2004.

7. Zhang G, Oldroyd SD, Huang LH, Yang B, Li Y, Ye R and El Nahas AM: Role of apoptosis and Bcl-2/Bax in the development of tubulointerstitial fibrosis during experimental obstructive nephropathy. Exp Nephrol 9: 71-80, 2001.

8. Liu CF, Liu H, Fang Y, Jiang SH, Zhu JM and Ding XQ: Rapamycin reduces renal hypoxia, interstitial inflammation and fibrosis in a rat model of unilateral ureteral obstruction. Clin Invest Med 37: E142, 2014.

9. Miyajima A, Chen J, Lawrence C, Ledbetter S, Soslow RA, Stern J, Jha S, Pigato J, Lemer ML, Poppas DP, et al: Antibody to transforming growth factor-beta ameliorates tubular apoptosis in unilateral ureteral obstruction. Kidney Int 58: 2301-2313, 2000.

10. Gao X, Mae H, Ayabe N, Takai T, Oshima K, Hattori M, Ueki T, Fujimoto J and Tanizawa T: Hepatocyte growth factor gene therapy retards the progression of chronic obstructive nephropathy. Kidney Int 62: 1238-1248, 2002.

11. Morrissey J, Hruska K, Guo G, Wang S, Chen Q and Klahr S: Bone morphogenetic protein-7 improves renal fibrosis and accelerates the return of renal function. J Am Soc Nephrol 13 (Suppl 1): S14-S21, 2002

12. Fu JH, Yang S, Nan CJ, Zhou CC, Lu DQ, Li S and Mu HQ MiR-182 affects renal cancer cell proliferation, apoptosis, and invasion by regulating $\mathrm{PI} 3 \mathrm{~K} / \mathrm{AKT} / \mathrm{mTOR}$ signaling pathway. Eur Rev Med Pharmacol Sci 22: 351-357, 2018.

13. Harvey SJ, Jarad G, Cunningham J, Goldberg S, Schermer B, Harfe BD, McManus MT, Benzing $\mathrm{T}$ and Miner JH: Podocyte-specific deletion of dicer alters cytoskeletal dynamics and causes glomerular disease. J Am Soc Nephrol 19: 2150-2158, 2008

14. Ho JJ and Marsden PA: Dicer cuts the kidney. J Am Soc Nephrol 19: 2043-2046, 2008.

15. Wang Y and Lee CG: MicroRNA and cancer - focus on apoptosis J Cell Mol Med 13: 12-23, 2009.

16. Hermeking H: The miR-34 family in cancer and apoptosis. Cell Death Differ 17: 193-199, 2010
17. Qi R, An H, Yu Y, Zhang M, Liu S, Xu H, Guo Z, Cheng T and Cao X: Notch1 signaling inhibits growth of human hepatocellular carcinoma through induction of cell cycle arrest and apoptosis. Cancer Res 63: 8323-8329, 2003.

18. Bommer GT, Gerin I,Feng Y, Kaczorowski AJ, Kuick R, Love RE, Zhai Y, Giordano TJ, Qin ZS, Moore BB, et al: p53-mediated activation of miRNA34 candidate tumor-suppressor genes. Curr Biol 17: 1298-1307, 2007

19. Ratajczak J, Wysoczynski M, Hayek F, Janowska-Wieczorek A and Ratajczak MZ: Membrane-derived microvesicles: Important and underappreciated mediators of cell-to-cell communication. Leukemia 20: 1487-1495, 2006.

20. Graves LE, Ariztia EV, Navari JR, Matzel HJ, Stack MS and Fishman DA: Proinvasive properties of ovarian cancer ascites-derived membrane vesicles. Cancer Res 64: 7045-7049, 2004.

21. Skog J, Würdinger T, van Rijn S, Meijer DH, Gainche L, Sena-Esteves M, Curry WT Jr, Carter BS, Krichevsky AM and Breakefield XO: Glioblastoma microvesicles transport RNA and proteins that promote tumour growth and provide diagnostic biomarkers. Nat Cell Biol 10: 1470-1476, 2008.

22. Taylor DD and Gercel-Taylor C: MicroRNA signatures of tumorderived exosomes as diagnostic biomarkers of ovarian cancer. Gynecol Oncol 110: 13-21, 2008

23. Bryant RJ, Pawlowski T, Catto JW, Marsden G, Vessella RL, Rhees B, Kuslich C, Visakorpi T and Hamdy FC: Changes in circulating microRNA levels associated with prostate cancer. $\mathrm{Br}$ J Cancer 106: 768-774, 2012.

24. Cole KA, Attiyeh EF, Mosse YP, Laquaglia MJ, Diskin SJ, Brodeur GM and Maris JM: A functional screen identifies miR-34a as a candidate neuroblastoma tumor suppressor gene. Mol Cancer Res 6: 735-742, 2008.

25. Hengartner MO: The biochemistry of apoptosis. Nature 407: 770-776, 2000.

26. Chen CC and Lau LF: Deadly liaisons: Fatal attraction between $\mathrm{CCN}$ matricellular proteins and the tumor necrosis factor family of cytokines. J Cell Commun Signal 4: 63-69, 2010.

27. Borges FT, Melo SA, Özdemir BC, Kato N, Revuelta I, Miller CA, Gattone VH II, LeBleu VS and Kalluri R: TGF- $\beta 1$-containing exosomes from injured epithelial cells activate fibroblasts to initiate tissue regenerative responses and fibrosis. J Am Soc Nephrol 24: 385-392, 2013. International (CC BY-NC-ND 4.0) License. 